\title{
ASSESSMENT OF HOUSEHOLD ENERGY UTILIZED FOR COOKING IN IKEJA, LAGOS STATE, NIGERIA
}

\author{
E. Emagbetere ${ }^{1, *}$, J. Odia ${ }^{2}$ and B. U. Oreko ${ }^{3}$ \\ 1,3 Dept. of Mechanical Engineering, Federal Univ. of Petroleum Resources, EFfurun, Delta State. NigERIA.

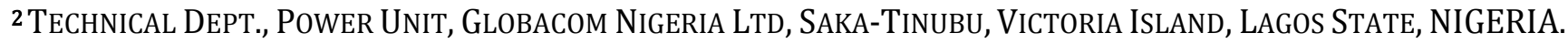 \\ E-mail addresses: ${ }^{1}$ emagbetere.eyere@fupre.edu.ng, ${ }^{2}$ get2odia@gmail.com, ${ }^{3}$ oreko.benjamin@fupre.edu.ng
}

\begin{abstract}
Household cooking energy accounts for a major part of the total energy consumed in Nigeria. Factors affecting the choice of Household energy utilized for cooking and the type preferred in Ikeja area of Lagos state were investigated in this study. Data were obtained through oral interview and administration of structured questionnaire on 250 randomly sampled households in the study area. MATLAB was used to conduct descriptive statistics, inferential statistics and percentage difference between used energy and preference energy. The study revealed that kerosene and Gas (LPG) were mostly used for daily cooking (48.60\%) and (36.30\%) respectively. Only a small proportion use Charcoal, firewood and electricity for their daily cooking, the percentage being 7.10\%, $5.7 \%$ and $2.4 \%$ for charcoal, firewood and electricity respectively. However preference rating of household energy was highest in Gas followed by electricity, kerosene, charcoal and firewood respectively. Chi-test, linear-by-linear relationship test, likelihood ratio test revealed that level of income, level of education and type of employment affects the choice of fuel used for cooking and the type preferred.
\end{abstract}

Keywords: household, cooking energy, MATLAB®, data, analysis

\section{INTRODUCTION}

Household cooking energy is the energy utilized for cooking and does not includes energy used for food processing and preparation before purchase [1]. It is a major part of the total energy consumed at home. The energy for cooking can be classified into solid fuels and non-solid fuels. The solid fuels include fossil fuels (coal, peat) and biomass (wood, dungs and agricultural products), while the nonsolid fuels consist of kerosene, liquefied natural gas and electricity [2]. The use of some solid fuels has been associated with indoor pollution and unsafe levels of toxic emission [3]. Apart from environmental pollution, forest degradation has been traced to collection of wood for firewood or charcoal production in certain locations, especially near cities and major roads $[4,5,8]$. To this day, many people remain dependent on traditional biomass fuels for cooking. In Osogbo for instance, up to 88 percent of 120 households investigated by Adetunji M. O. et al [2] depends on firewood and charcoal for cooking. Several factors may be responsible for their choices of energy and energy of preference for cooking.

There are a good number of reports on choices of energy for household's cooking and the factors affecting their preference. Some researchers adopt energy ladder model for their investigation. The energy ladder model is a scale which rates the quality of household fuels [9]. It represents fuel types that might be used by households as their income increases [10]. For the ladder model, a fuel has strong dependency on income of a household and it assumes that switching from one fuel is an abandonment of the previously used fuel [11] whereas, other factors such as culture, social desirability and security of supply affects the energy choice for households cooking [12, 13]. Many studies have shown that choice of household energy for cooking varies from place to place. For example, electricity and biomass are the most common fuel types used in urban China households [14] while the simultaneous use of firewood and LPG for cooking is a common practice in urban areas of Guatemala [15]. In India, use of biomass 
fuel stove for baking traditional breads is common in wealthy households [18]. In certain regions of Mexico, households irrespective of their income level cook a particular kind of food (tortillas) over an open wood fire rather than using an LPG stove because of the utility they derive from the taste and texture provided by wood cooking $[17,18]$

In Nigeria, price of fuel was shown to affect the choice of fuel for most households. Fawehinmi B. D. et al [20] used a descriptive statistical approach to demonstrate the effect of increased cost of modern fuel on the level of poverty in Nigeria which has favoured the choice of firewood energy for most households cooking. Some studies in their attempt to assess the household energy consumption in Nigeria discovered that household cooking fuel mostly used is firewood. The reasons for their choices were basically availability and affordability. These studies however focused on undeveloped rural areas in Nigeria [19]. There is scarcity of information on household energy statistics in urban areas of Nigeria. Yakub J. O. et al [21] attempted to assess the household energy for cooking in Ikeja area of Lagos state which is an urban city. However, in his studies, only few respondents were considered in the sample area.

The aim of this work is to assess the type of household energy utilized for cooking and the actual type preferred. Also to investigate the effect of: level of income, level of education and nature of job of households on the type of household cooking energy utilized and actual type they prefer to use in Ikeja area of Lagos state.

\section{METHODOLOGY}

\subsection{Preamble}

This work was majorly by oral interview and survey involving questionnaires administration designed to gather relevant information from households' cook and energy suppliers.

\subsection{Study Area}

The study was conducted in Ikeja metropolitan area of Lagos State, Nigeria. Ikeja which is the State capital of Lagos State, is located between latitude 6 ${ }^{\circ} 36^{\prime} 38^{\prime \prime}$ North of the equator and longitude $3^{\circ} 15^{\prime} 21^{\prime \prime}$ east of the Greenwich meridian. It has a population of 313,196 . Ikeja Metropolis is made up of two Local Government; Ikeja Local government (Ikeja 1) and Local Council Development Area (Ikeja 2). Both Ikeja 1 and Ikeja 2 have 6 wards each making a total of 12 wards that make up the metropolis. The major reason for selecting this location for the research is the equivalent spacing among respondents which favours even distribution of questionnaires. 21 households were randomly selected per ward. This made a total of 252 households.

\subsection{Survey Instrument}

The main instrument used for the survey was the questionnaire designed to gather the required information from respective households' cook. The questionnaire consists of four main sections for the general information on respondent's demography, knowledge of energy source and preference, availability of cooking energy and ease of use, and degree of energy usage. Oral interview was also done in the study area. Suppliers of the various cooking fuel (LPG, kerosene, firewood, Electricity and Charcoal) were interviewed orally to get their respective prices.

\subsection{Questionnaire Information}

Data were obtained on the demographic characteristics of the households, energy preferred for cooking, energy utilized for cooking, knowledge of energy preferences, availability of the cooking energy used, energy usage and other factors affecting energy consumption pattern. The questionnaires were administered to persons who are responsible for cooking in the sampled households. Out of the 250 questionnaires administered, only 225 (90\%) were retrieved. Due to incomplete information or nonresponse to some vital questions, the study made use of data from 212 households for the analysis.

\subsection{Information Analysis}

The analytical tools employed for the study were descriptive statistics, inferential statistics (chi-test, linear-by-linear relationship test, likelihood ratio and the Pearson Correlation test) and percentage difference between used energy and preference energy. MATLAB was used to analyze the data.

\section{RESULTS AND DISCUSSIONS}

\subsection{Percentage Distribution of Energy Used by Respondents}

As shown in Table 1, households prefer cleaner energy for cooking, the price to a large extent affects their choice of usage, hence most households for price sake use kerosene despites its tendency to blacken pots. The high cost of electricity and the risk involved is possibly the reason it is the least used for of cooking. 
This finding reveals that people prefer more convenient and cleaner energy for cooking. More so, that there is a correlation between the choice of cooking energy and the value of men or women's time. This is because men or women who work in the office demand more convenience in their use of household energy for cooking. The LPG and kerosene are preferred to traditional Biomass energy such as fuel wood and charcoal, price availability and the ease of use have also been identify as important factors affecting the choice of energy for cooking [22].

\subsection{Satisfaction with Energy Used by Respondent}

Figure 1 shows the wiliness of respondent to change their energy used for cooking if possible. As observed, majority of people using LPG were satisfied (79\%) due to its high speed, convenience and smokeless characteristics, however some were dissatisfied because of its cost implication. Although kerosene is the mostly used fuel as shown in Table 5, it does not burn completely when used as fuel, producing much soot. Consequently, only half of respondents using kerosene (50\%) are satisfied with its usage despite its low cost. About $58 \%$ of the few respondents who use electricity for cooking are unsatisfied. This may be due to its erratic supply. Firewood produces much undesirable smoke when used, more-so, its usage requires the most effort to set up, hence a majority (90\%) of its users are unsatisfied with its usage. For charcoal, users were not satisfied because of its uncleanness, however some derived their satisfaction from its low cost and availability, hence $50 \%$ of its users indicated that they are satisfied with its usage.

\subsection{Preference Rating of Household Energy Used for Cooking}

The preference rating of energy for cooking and the reason given for their preference are as shown in the Table 1.



Figure 1: Satisfaction with Energy Used for Cooking
LPG was most preferred for cooking in the study area reason being more convenience $(33.90 \%)$, vary fast $(30.50 \%)$, no smoke $(15.30 \%)$, readily available (13.60\%), low price and no ash are $2.5 \%$ and $1.7 \%$ respectively. Electricity ranked $2^{\text {nd }}$ with the following reasons; more convenient $(56.10 \%)$, low price (19.50\%), vary fast (14.60\%), no smoke $(7.30 \%)$ and readily available $(2.40 \%)$. Kerosene as preferred household cooking energy ranked $3^{\text {rd }}$ reasons being low price $(46.20 \%)$, convenience $(33.30 \%)$ readily available $(12.80 \%)$, easy to ignite, no ash and vary fast $(2.60 \%)$. Charcoal ranked $4^{\text {th }}$ the following reasons were given for its preference; readily available (66.70\%) and low price (33.3\%). Preference of fuel wood ranked $5^{\text {th }}$ with the following reasons for its preference are; low price (54.50\%), convenience (27.30\%) and readily available (18.20\%).

Respondents utilize energy sources that are contrary to their preference, Kerosene which ranked $3^{\text {rd }}$ as respondent preference was mostly utilized by (48.6\%) of the respondent, while LPG which ranked $1^{\text {st }}$ in its preference but was utilized by $(36.30 \%)$ of the respondent reason could be high upfront cost of the stove and cylinder which keep poor people out of it because they cannot put together the sufficient capital. Electricity which ranked $2^{\text {nd }}$ in preference was least utilized by $(2.4 \%)$ of the respondent. The major reason that could be adduced is that electricity is not readily available. Erratic electricity supply has been the most frustrating and disturbing infrastructural constrain to economic development of Nigeria via economy deregulation policy and huge resources it has gulped.

\subsection{Type of Energy Used and Preferred as a Function of Income}

This section discusses the effect of people's income on their choice of preferred energy type and used.

3.4.1 Distribution of Household Incomes: Figure 2 below shows that only a few respondents do not have monthly income (1.4\%). $35.40 \%$ of respondents are low income earners (monthly income less than $\# 50,000$ ). $38.8 \%$ of respondent are average income earners (between 50,000 and 200,000 naira per month). $24.40 \%$ are high income earners (over 200,000 naira). It is thus deduced that People in the considered area are more likely to be average monthly income earners while residents in the area considered are very unlikely to be zero income earners. 
Table 1: Energy Preference and Reasons for Preference

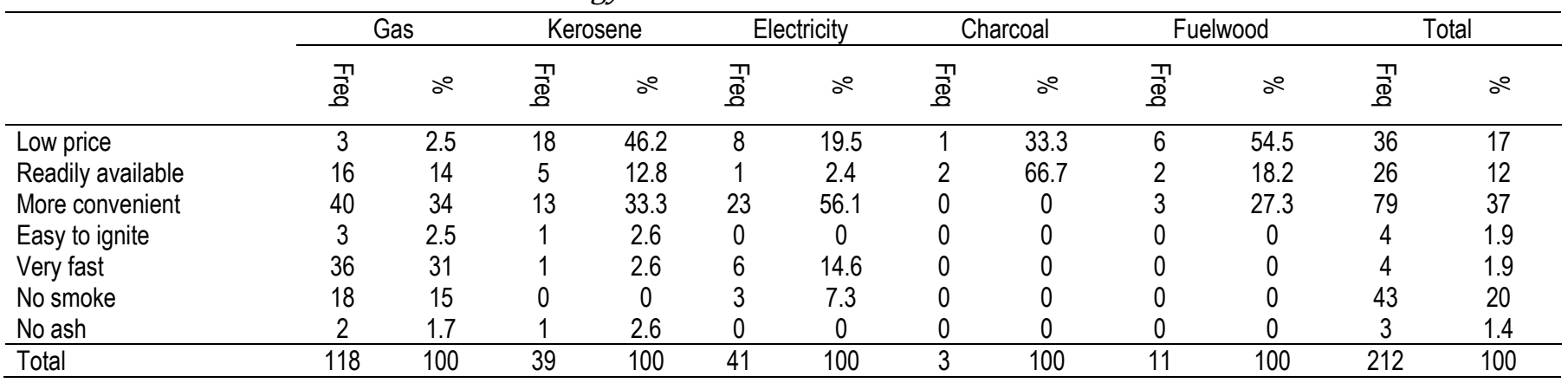

Source: Field Survey

Table 2: The Energy Use and Energy Preferred for Different Income Level of Respondents

\begin{tabular}{|c|c|c|c|c|c|c|c|c|c|c|c|c|c|c|c|}
\hline & \multicolumn{3}{|c|}{ Gas } & \multicolumn{3}{|c|}{ Kerosene } & \multicolumn{3}{|c|}{ Electricity } & \multicolumn{3}{|c|}{ Charcoal } & \multicolumn{3}{|c|}{ Fuel wood } \\
\hline & 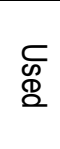 & 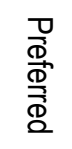 & 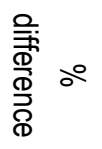 & 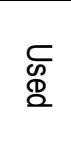 & 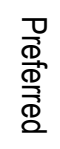 & 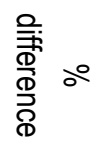 &  & 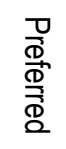 & $\begin{array}{l}\frac{0}{\bar{D}} \\
\frac{\mathbb{D}}{\mathbb{D}} \\
\frac{\mathbb{D}}{D}\end{array}$ & 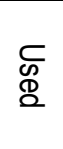 & 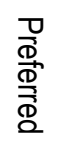 & 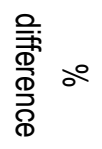 & 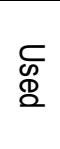 & $\begin{array}{l}\text { 명 } \\
\frac{\mathbb{D}}{\mathbb{D}} \\
\stackrel{\mathbb{D}}{\mathbb{D}}\end{array}$ & 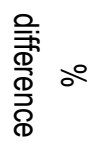 \\
\hline Less than N50000 & 9 & 30 & 233 & 49 & 19 & -61 & 1 & 17 & 1600 & 4 & 2 & -50 & 11 & 6 & -45 \\
\hline $500000-100000$ & 26 & 39 & 50 & 42 & 16 & -61 & 3 & 20 & 566 & 10 & 1 & -90 & 0 & 5 & 0 \\
\hline $100000-250000$ & 38 & 44 & 15 & 11 & 4 & -63 & 1 & 3 & 200 & 0 & 0 & 0 & 1 & 0 & -100 \\
\hline No monthly salary & 1 & 3 & 200 & 1 & 0 & -100 & 0 & 0 & 0 & 1 & 0 & -100 & 0 & 0 & 0 \\
\hline Total & 74 & 116 & 56 & 103 & 39 & -62 & 5 & 40 & 700 & 15 & 3 & -80 & 12 & 11 & -8 \\
\hline
\end{tabular}

\subsubsection{Energy Use and Preferred Energy Compared for} Income Level: As observed from Table 2, most respondents with high and low income earning are satisfied with the energy used for cooking. Although majority of people are willing to change their cooking energy for health reason. Low income earners mostly used kerosene for cooking; however they prefer gas and electricity for cooking. Medium income earner mostly used kerosene and LPG; however they prefer LPG and electricity. High income earners mostly use LPG which they prefer. The high preference for LPG is due to its clean nature, speed and convenience. High utilization of kerosene is due to its low cost and availability.

3.4.3 Relationship between Level of Income, and Energy used and Preference: From Table 3, it can be deduced that there exist significant relationship between people's income level and type of energy used as the Chi - Test value $=73.796$ and 32.170 , with $\mathrm{P}<0.05$ for both used and preferred household cooking energy respectively. The likelihood ratio tests show that the income level of people will affect the type of energy they used as well as the type of energy they will prefer (with $\mathrm{P}<0.05$ for both cases).

The Linear by linear association tests show that the likelihood that a person's choice of a particular energy used and preferred is affected by his/her income level ( $\mathrm{P}<0.05$ for both cases). The Pearson correlation tests show that there is a relationship between income level of people and energy usage and preference respectively ( $\mathrm{P}<0.05$ for both cases).

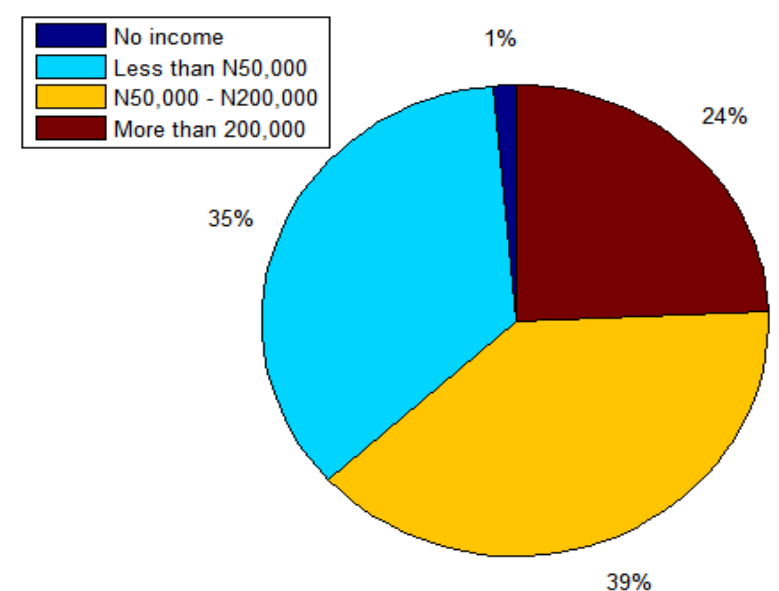

Figure 2: Classification of Respondents by Income level

Table 3: Test Results of Association and Relatedness of Energy Use and Preferred Energy for Income Level

\begin{tabular}{lcccc}
\hline \multirow{2}{*}{\multicolumn{1}{c}{ Method }} & \multicolumn{2}{c}{ Energy Use } & \multicolumn{2}{c}{ Preferred Energy } \\
\cline { 2 - 5 } & Value & Sig & Value & Sig \\
\hline Pearson Chi-Square & 73.796 & 0.000 & 32.170 & 0.001 \\
Likelihood Ratio & 77.857 & 0.000 & 37.759 & 0.000 \\
Linear-by-Linear Association & 26.437 & 0.000 & 20.505 & 0.000 \\
\hline
\end{tabular}




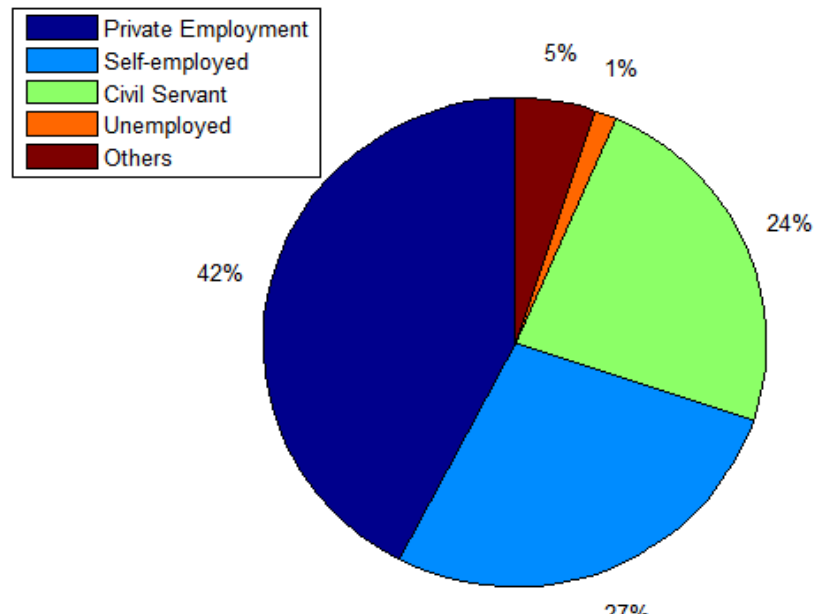

Figure 3: Distribution of Respondents Employment Status

Table 4: Test of Association and Relatedness of Energy Used and Preferred Energy for Employment Type

\begin{tabular}{lllll}
\hline \multirow{2}{*}{ Method } & \multicolumn{2}{l}{ Energy Use } & \multicolumn{2}{l}{ Preferred Energy } \\
\cline { 2 - 5 } & Value & Sig & Value & Sig \\
\hline Pearson Chi-Square & 47.589 & 0.000 & 63.990 & 0.000 \\
Likelihood Ratio & 51.86 & 0.000 & 47.791 & 0.000 \\
Linear-by-Linear Association & 16.475 & 0.000 & 8.912 & 0.003 \\
Pearson Correlation & 0.279 & 0.000 & 0.206 & 0.003 \\
\hline
\end{tabular}

\subsection{Energy Use and Preference as a Function of Type of Employment}

\subsubsection{Percentage Distribution of Respondents} Employment Types: Figure 3 show that only a few respondents are unemployed (1.4\%). $42.5 \%$ of respondents are employed in private firms. $27.4 \%$ of respondent run their private business. $23.60 \%$ are civil servants while only $5.2 \%$ do other things for a living. It is thus deduced that People in the considered area are more likely to be working in a private firm, self-employed or civil servants.

\subsubsection{Relationship between Energy Use and Preferred} Energy Compared to Employment Status: As shown in Table 4 The Chi-tests show that there exist significant relationship between people's employment type and type of energy used (Chi - Test value $=73.796, \mathrm{P}<$ $0.05)$ as well as preferred energy (Chi - Test value $=$ $32.170, \mathrm{P}<0.05)$. The likelihood ratio tests show that people's type of employment will affect the type of energy they used as well as the type of energy they will prefer $(\mathrm{P}<0.05$ for both cases). The Linear by linear association tests show that the likelihood that a person's choice of a particular energy used and preferred is affected by his/her type of employment ( $\mathrm{P}$ $<0.05$ for both cases). The Pearson correlation tests show that there is a relationship between a person's employment type and energy usage and preference respectively ( $\mathrm{P}<0.05$ for both cases)..

\subsubsection{Energy Use and Preferred Energy Compared to Type of Employment}

As observed in Table 5 below, majority of respondents who are employed in private firms use LPG. This may be because of their relatively high income. Some however, use kerosene for cost reasons. Majority of the respondents who are self-employed make use of kerosene as their cooking fuel. Civil servants mostly used kerosene despite their preference for gas because most of them are low income earners.

\subsection{Type of Energy Utilized and Preferred as a Function of Education level}

\subsubsection{Distribution of Respondents' Level of Education:} Figure 4 show that only a few respondents are uneducated (1.9\%). $59.90 \%$ of respondents have tertiary education. $21.20 \%$ of respondents have secondary education while $17 \%$ have other forms of education. It is thus deduced that a large number of people in the considered area have a form of education as only very few has primary education.

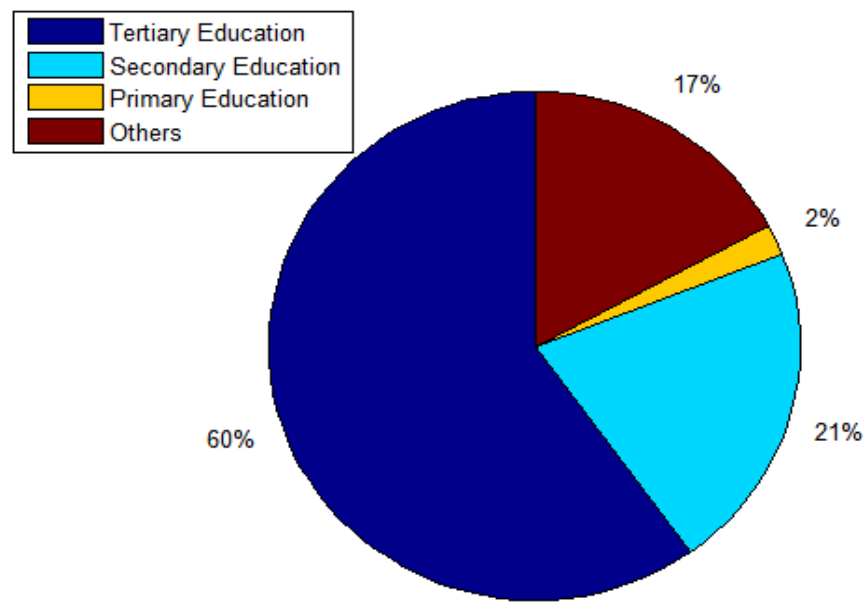

\section{Figure 4: Distribution of Respondent by Education}

3.6.2 Relationship between Education, and Energy Use and Preference: Table 6 shows the chi-test, linear-bylinear relationship test, likelihood ratio test and the correlation test for respondents' educations' level as it affects choice of energy used for cooking and preferred choice of energy. The Chi-tests show that there exist significant relationship between people's educations' level and type of energy used $(\mathrm{P}<0.05)$ as well as preferred energy $(\mathrm{P}<0.05)$. The likelihood ratio tests show that people's level of education will 
affect the type of energy they used as well as the type of energy they will prefer ( $\mathrm{P}<0.05$ for both cases). The Linear by linear association tests show that the likelihood that a person's choice of a particular energy use and preferred is affected by his/her level of education ( $\mathrm{P}<0.05$ for both cases). The Pearson correlation tests show that there is a relationship between people's education level and energy usage and preference respectively $(\mathrm{P}<0.05$ for both cases)

Table 6: Test Results of Association and Relatedness of Type of Energy Utilized and Energy Preferred for educational level

\begin{tabular}{lllll}
\hline & \multicolumn{2}{l}{ Energy Use } & \multicolumn{2}{l}{ Preferred Energy } \\
\cline { 2 - 5 } & Value & Sig & Value & Sig \\
\hline Pearson Chi-Square & 53.87 & 0.000 & 40.842 & 0.000 \\
Likelihood Ratio & 56.022 & 0.000 & 42.902 & 0.000 \\
Linear-by-Linear Association & 16.642 & 0.000 & 9.492 & 0.002 \\
Pearson Correlation & 0.281 & 0.000 & 0.212 & 0.002 \\
\hline
\end{tabular}

\subsubsection{Energy Use and Preferred Energy Compared For}

Educational Level: Table 7 shows energy use and preferred compared for education level. Majority of respondent are educated in the study area as most people have at least secondary education. People who has tertiary education used LPG and kerosene, although with a high preference for LPG probably due to their level of education and exposure. People with secondary education mostly used kerosene with their high preference for LPG this is due to lack of awareness of potential benefit that would compensate for cost implication involve in it.

\section{CONCLUSION}

The study showed that in the study area, Kerosene was mostly utilized for cooking by households, follow by LPG, charcoal, firewood and electricity respectively. However, most people are not satisfied with their type of cooking energy. The most preferred energy for cooking is LPG follow by electricity, kerosene, charcoal and firewood respectively. There is a significant relationship between the income of household and the type of energy used for cooking.

An evenly distributed level of income is observed among people. Most people with high and low income earning are satisfied with the energy used for cooking. Low income earners mostly used kerosene for cooking; however they prefer gas and electricity for cooking. Medium income earner mostly used kerosene and LPG; however they prefer gas and electricity.

Table 5 Energy Use and Preferred Energy Compared to Type of Employment

\begin{tabular}{|c|c|c|c|c|c|c|c|c|c|c|c|c|c|c|c|}
\hline & \multicolumn{3}{|c|}{ Gas } & \multicolumn{3}{|c|}{ Kerosene } & \multicolumn{3}{|c|}{ Electricity } & \multicolumn{3}{|c|}{ Charcoal } & \multicolumn{3}{|c|}{ Fuel wood } \\
\hline & 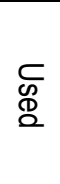 & 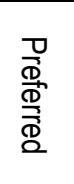 & 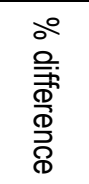 & 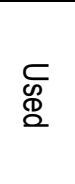 & 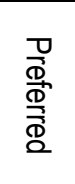 & 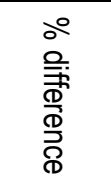 & $\begin{array}{l}\text { C } \\
\text { d } \\
\stackrel{2}{2}\end{array}$ & 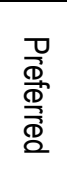 & 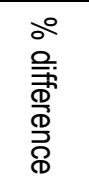 & $\begin{array}{l}\text { C } \\
\text { d } \\
\stackrel{2}{2}\end{array}$ & 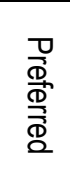 &  & 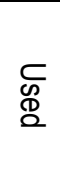 &  & 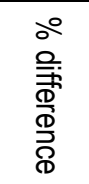 \\
\hline Private Employment & 50 & 62 & 24 & 35 & 10 & -71.43 & 2 & 18 & 800 & 3 & 0 & -100 & 0 & 0 & 0 \\
\hline Self-Employment & 16 & 26 & 62.5 & 33 & 18 & -45.45 & 1 & 10 & 900 & 3 & 1 & -66.7 & 5 & 3 & -40 \\
\hline Civil Servant & 6 & 24 & 300 & 29 & 7 & -75.86 & 1 & 11 & 1000 & 7 & 0 & -100 & 7 & 8 & 14.29 \\
\hline Unemployed & 0 & 0 & 0 & 2 & 2 & 0 & 0 & 0 & 0 & 1 & 1 & 0 & 0 & 0 & 0 \\
\hline Others & 5 & 6 & 20 & 4 & 2 & 1 & 1 & 2 & 100 & 1 & 1 & 0 & 0 & 0 & 0 \\
\hline Total & 77 & 118 & 53.25 & 103 & 39 & -62.14 & 5 & 41 & 720 & 15 & 3 & -80 & 12 & 11 & -8.33 \\
\hline
\end{tabular}

Table 7: Energy Used and Preferred Energy Compared for Different Educational level

\begin{tabular}{|c|c|c|c|c|c|c|c|c|c|c|c|c|c|c|c|}
\hline & \multicolumn{3}{|c|}{ Gas } & \multicolumn{3}{|c|}{ Kerosene } & \multicolumn{3}{|c|}{ Electricity } & \multicolumn{3}{|c|}{ Charcoal } & \multicolumn{3}{|c|}{ Fuelwood } \\
\hline & 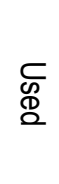 &  & 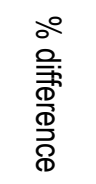 & 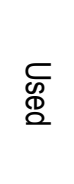 & 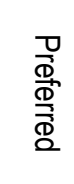 & 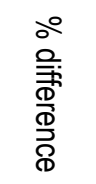 & 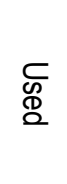 & 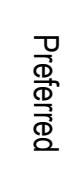 & 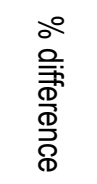 & $\begin{array}{l}\text { C్ } \\
\text { 足 }\end{array}$ & 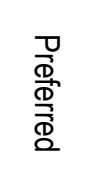 &  &  & 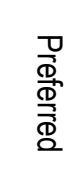 & 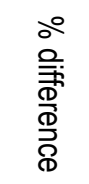 \\
\hline Tertiary Education & 64 & 82 & 28.13 & 53 & 22 & -58.5 & 3 & 23 & 666.7 & 7 & 0 & -100 & 0 & 0 & 0 \\
\hline Secondary Education & 9 & 18 & 100 & 24 & 8 & -66.7 & 1 & 12 & 1100 & 2 & 1 & -50 & 9 & 6 & -33.3 \\
\hline Primary Education & 0 & 1 & 1 & 3 & 0 & -100 & 0 & 3 & 0 & 0 & 0 & 0 & 1 & 0 & -100 \\
\hline Others & 4 & 17 & 17 & 23 & 9 & -60.9 & 1 & 3 & 200 & 6 & 2 & -66.7 & 2 & 5 & 150 \\
\hline Total & 77 & 118 & 53.25 & 103 & 39 & -62.1 & 5 & 41 & 720 & 15 & 3 & -80 & 12 & 11 & -8.33 \\
\hline
\end{tabular}


High income earners mostly use LPG which they prefer. The high preference for LPG is due to its clean nature, speed and convenience. High utilization of kerosene is due to its low cost and availability.

The type of employment of people ranging from private employed, self-employed, civil servant and unemployed also affect the choice of energy. Majority of people who were gainfully employed used LPG which they also prefer. However some use kerosene for cost reason. Majority of self-employed used kerosene for their cooking. Civil servants mostly used kerosene despite their preference for gas because they are low income earner.

Majority of people were educated in the study area as most people have at least secondary education. People with tertiary education used LPG and kerosene, although with a high preference for LPG probably due to their level of education and exposure. People with secondary education mostly used kerosene with their high preference for LPG this is due to lack of awareness of potential benefit that would compensate for cost implication involve in it.

\section{REFERENCES}

[1] Adetunji, M .O., Adesiyan, I. O. and Sanusi, W. A. "Household Energy Consumption Pattern in Osogbo Local Government Area of Osun State", Pakistan Journal of Social Sciences, Vol. 4, Number. 1, 2007, pp.9-13.

[2] Sathaye, J., Ghirardi, A. and Schipper, L. "Energy Demand in Developing Countries: A Sectorial Analysis of Recent Trends", Annual review of Energy, Vol. 12, number 1, 1997, pp253-281.

[3] Masayasu, I. and Takamasa, A. “Energy Demand in Five Major Asian Developing Countries: Structure and Prospects", World Bank publications, 277 Washington D.C., 1995.

[4] Energy Sector Management Assistance program (ESMAP), "Sustainable wood fuel supplies from the dry tropical woodlands", ESMAP Technical paper, Washington DC, June 13, 2001. http://documents.worldbank.org/curated/en/879 341468758396173/sustainable-woodfuelsupplies-from-the-dry-tropical-woodlands, Assessed on January 15, 2016.

[5] Heltberg, R. "Determinants and Impact of Local Institutions for Common Resource Management", Environment and Development Economics, vol. 6 number 2, 2001, pp.183-208.

[6] Sambo, A. S. "Report of the Rural Energy Survey in Selected local government Areas of Kano, Katsina, Niger and Sokoto State as well as in the Federal
Capital Territory, Abuja”, 1991, www.isesco.org.ma/doc/A.S.Sambo.pdf, Assessed December 8, 2015.

[7] Sanda, A. U., Sambo, A. S. and Mika, I. A. S. "Fuel Wood Consumption Pattern in Fakai district, A lesson for Rural Energy Planning and Policy in Nigeria", Nigerian Journal of Renewable Energy, vol. 2 number 1, 1991, pp. 54-59.

[8] Alli, S., Sambo, A. S. and Asere, A. A., "Household Energy Consumption around Bauchi Metropolis and Environs", Nigerian Journal of Tropical Engineering, vol. 2, number 1, 2001, pp. 37-48.

[9] Chambwera, M. "Economic Analysis of Urban fuelwood Demand: the case of Harare in Zimbabwe", Ph.D thesis of Wageningen University, Wageningen, The Netherlands, 2004, pp52-165

[10] Sheilah, M. and Bannister, A. "Energy, Poverty and Sustainable Urban Livelihoods", Development Planning Unit (DPU), Working Paper No.126, ISSN: 1474-3280, University College London, 2003.

[11] Leach, G. "The Energy Transition", Energy Policy, Vol. 20, Number 2, 1992, pp.116-123.

[12] Davis, M. "Rural Household Energy Consumption: The Effects of Access to Electricity - Evidence from South Africa", Energy Policy, vol. 26 Number 3, 1998, pp.207-217.

[13] Barnett, A. "Energy and the fight against poverty", Department for International Development (Dfid), Livelihood Sector Report, UK. 2000.

[14] Leiwen, J. and O’Neill, B. C. “The Energy Transition in Rural China", International Institute for Applied Systems Analysis (IIASA), IR(Interim Report)- 03070, 2003. http://pure.iiasa.ac.at/7015 Assessed on January 28, 2016

[15] Energy Sector Management Assistance program (ESMAP), "Household Energy Use in Developing Countries: A Multicountry Study", ESMAP Technical paper, Washington DC, 2003. http://documents.worldbank.org/curated/en/560 761468780297294/Household-energy-use-indeveloping-countries-a-multicountry-study, Assessed on January 28, 2016.

[16] Preet, M., Dutta S., Pal, R. C., Sharma, S. and Ramana, V., "Rural Energy Matters: The Dhanawas Experience". The Energy Research Institute, New Delhi, India, 2000.

[17] Masera, O. O., Saatkamp, B. D. and Kammen, D. M. "From Linear Fuel Switching to Multiple Cooking Strategies: A Critique and Alternative to the Energy Ladder Model." World Development, Vol. 28, Number. 2. 2000. Pp.2083-2103.

[18] Saatkamp, B. D., Masera, O. O. and Daniel, M. K. "Energy and Health Transitions in Development: Fuel Use, Stove Technology and Morbidity in 
Jaracuaro, Mexico", Energy for Sustainable Development. Vol. 4, Number. 2. 2000, pp.7-16.

[19] Alabe, M. "Household Energy Consumption Pattern in Northern Nigeria", Energy for Sustainable Development, ISSN: 0975-08265, 1996, pp.42-45.

[20] Fawehinmi, A.S. and Oyerinde, O.U. "Household Energy in Nigeria: The Challenge of Pricing and Poverty in Fuel Switching", Journal of Energy Development, vol. 27, 2002, Pp.277-284
[21] Yaqub, J.O., Olateju, A.O. and Aina, B. "A Comparative Analysis of Household Energy Use in Nigeria: A Case Study of Ikeja and Oke-Oko Area in Ikorodu Areas of Lagos State", 2011, www.naee.org/ng Assessed on October 12, 2015.

[22] Dzioubinski O. and Chipman R., "Trends in Consumption and Production: Household Energy Consumption". Discussion Paper of the United Nations Department of Economic and Social Affairs, 1999, pp 21

\section{APPENDIX}

\subsection{Questionnaire}

Dear Sir/Madam,

\section{QUESTIONNAIRE}

This questionnaire is for a research that bothers on household cooking energy usage and preference in Ikeja area of Lagos state. Kindly assist us by providing answers to the following questions. Any information you supplied will be treated as confidential.

SECTION A: (Measures of Demographic Variables) Please tick $(\sqrt{ })$ the appropriate answer as applicable and fill in the gaps where necessary
1. Sex:
(a) Male [ ]
(b) Female [ ]

2. Age:

(a) Below 19 [ ] (b) $20-29$ [ ] (c) $30-39$ [ ] (d) $40-49$ (e) Above 50 [ ]

3. Marital Status:

(a) Single [ ] (b) Married [ ] (c) Separated [ ] (d) Widowed [ ] (e) Divorced [ ]

4. Number of Children: $\quad$ (a) $1-4$ [ ] (b) 5-9 [ ] (c) $10-14$ [ ] (d) 15 and above [ ] (e) None [ ]

5. Level of Education: No formal education [ ] (b) Primary education [ ] (c) Secondary Education [ ] (d) Tertiary Education [ ] (e) Others [ ]

6. Occupation:

Civil Servant [ ] (b) Self Employed [ ] (c) Unemployed [ ] (d) Others [ ]

7. Income Per:

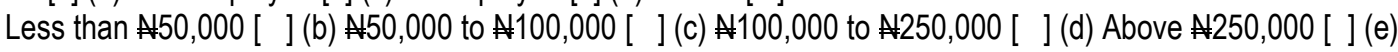

I do not earn any monthly income. [ ]

9. Which energy would you prefer for cooking?

(e) Sawdust [ ]

10. What type of Energy do you use in cooking?

(e) Sawdust [ ]

(a) Gas [ ] (b) Electricity [ ] (c) Kerosene [ ] (d) Charcoal [ ] (d) Firewood [ ]

(a) Gas [ ] (b) Electricity [ ] (c) Kerosene [ ] (d) Charcoal [ ] (d) Firewood [ ]

\section{SECTION B}

Kindly indicate by ticking $(\sqrt{ })$ the appropriate response at the right of each statement using the formats below.

\begin{tabular}{|ll|l|}
\hline \multicolumn{1}{|c|}{ Knowledge of Energy sources and preferences } & YES & NO \\
\hline 1. $\quad$ Are you familiar with other energy sources apart from the one you use? & & \\
\hline 2. $\quad$ Is your fuel source close to your home? & & \\
\hline 3. $\quad$ Does the cost of the energy type influence your preference for it? & & \\
\hline 4. $\quad$ Does your cooking energy produce smoke? & & \\
\hline 5. $\quad$ Do you consider cooking with your preferred energy source safe? & \\
\hline $6 . \quad$ Would you have preferred other energy sources if you could afford it? & \\
\hline 7. $\quad$ Are you satisfied with the energy type you use for cooking? & & \\
\hline 8. $\quad$ Do you consider your energy type cost effective? & & \\
\hline 9. & Do you consider your cooking energy source modern? & \\
\hline
\end{tabular}

\section{SECTION C}

Kindly indicate by ticking $(\sqrt{ })$ the appropriate response at the right of each statement using the formats below. $5=$ All of the time, $4=$ Most of the time, 3 = Some of the time, 2 = A little of the time, $1=$ None of the time.

\begin{tabular}{|c|c|c|c|c|c|c|}
\hline $\mathrm{S} / \mathrm{N}$ & & 5 & 4 & 3 & 2 & 1 \\
\hline 1. & How often do you use your energy type to cook? & & & & & \\
\hline 2. & How many times have you considered stopping the use of your energy type? & & & & & \\
\hline 3. & How often do you develop health problems due to the cooking type you use/? & & & & & \\
\hline 4. & How often has your neighbours complained because of the energy source you use? & & & & & \\
\hline 5. & How often do you consider your cooking better due to your energy source? & & & & & \\
\hline 6. & How often was there no availability of your cooking energy in your area? & & & & & \\
\hline
\end{tabular}

\section{SECTION D}

Kindly indicate by ticking $(\sqrt{ })$ the appropriate response at the right of each statement using the formats below. SA $=$ Strongly Agree; $A=$ Agree, $\mathrm{D}=$ Disagree, $\mathrm{SD}=$ Strongly Disagree 


\begin{tabular}{|c|c|c|c|c|}
\hline Availability of the cooking energy and ease of use & SA & A & $\mathrm{D}$ & SD \\
\hline 1. It is always difficult to get my cooking energy to buy & & & & \\
\hline 2. There is always shortage in supply of my cooking energy & & & & \\
\hline 3. More people in my area use the same cooking energy that I use & & & & \\
\hline 4. Availability of the cooking energy will make more people prefer it & & & & \\
\hline 5. Where I purchase my cooking energy is far from my home & & & & \\
\hline 6. I can always get my cooking energy to buy & & & & \\
\hline 7. I would love other energy sources but cannot afford it & & & & \\
\hline 8. I always enjoy cooking with my energy type & & & & \\
\hline 9. Cooking with my energy type makes me sick & & & & \\
\hline 10. There are complaints from my neighbours when I am cooking due to the energy type & & & & \\
\hline
\end{tabular}

